\title{
Kimyager Kevkep Reşat [Duruöz] Hanımın Kısa Süren Meslek Yaşamı
}

\section{Kevkep Reşat [Duruöz] and Her Brief Career in Chemistry}

\section{Şeref Etker ${ }^{1}$ (1)}

'Dr., İstanbul, Türkiye

ORCID: Ş.E. 0000-0001-6966-8816

Sorumlu yazar/Corresponding author: Şeref Etker,

Istanbul, Türkiye

E-posta/E-mail: serefetker@gmail.com

Başvuru/Submitted: 01.09.2019

Revizyon Talebi/Revision Requested:

28.09.2019

Son Revizyon/Last Revision Received:

10.10.2019

Kabul/Accepted: 04.11.2019

Online Yayın/Published Online: 03.01.2020

Atıf/Citation:

Etker, Şeref. "Kimyager Kevkep Reşat [Duruöz] Hanımın Kısa Süren Meslek Yaşamı." Osman/ı

Bilimi Araştırmaları 21, 1 (2020): 57-69

https://doi.org/10.26650/oba.613870

\section{öz}

Kevkep Reşat [Duruöz] 1906 yılında İstanbul'da doğmuştur. Babası İzettin Mehmet Reşat, Erenköy İnas Sultanisi ve Darülfünun Dişçi ve Eczacı Mektepleri Dahiliye Müdürlerindendir. Kevkep Reşat, Erenköy İnas Sultanisi'nden mezun olduktan sonra İstanbul Darülfünunu Fen Fakültesi'nden 1926 yılında kimyagerlik diploması almıştır. Ardından, 1927 yılında, Müderris Dr. Cevat Mazhar'ın yanına Kimya-yı Sınai-i Uzvi ve Hayati (Organik Sınai Kimya ve Biyokimya) asistanı olarak atanmıştır. Fen Fakültesi'nin ilk kadın asistanlarından biridir. Cevat Mazhar ve Hatice Bodur ile 'İstanbul yoğurdu' üzerine yaptığı bir araştırma 1932'de Almanca olarak Chemiker-Zeitung dergisinde yayımlanmıştır. Bu çalışma, 1933 öncesi Türkiye'de uygulamalı kimya konusunda yapılan ilk çalışmalardandır. Kevkep Reşat'ın kimya asistanlığı, 1933 Üniversite Reformu ile son bulmuştur. O yıldan sonra, İstanbul'daki ortaöğretim kurumlarında öğretmenlik yapmıştır. Notre Dame de Sion'da Türkçe, Tarih ve Coğrafya, Saint Benoît'da Türkçe dersleri vermiştir. 1936 yılında İstanbul'da Kumkapı Ortaokulu'nda Fen Bilgisi öğretmenliği vardır. Geçirdiği bir 'felç' nedeniyle, 1942 yılında öğretmenlikten ayrılmış, 1994 yılında vefat etmiştir.

Anahtar sözcükler: Kevkep Reşat, Hatice Kevkep Duruöz, İstanbul Darülfünunu Fen Fakültesi, Cevat Mazhar, kimya bibliyografyası, temel bilimler tarihi

\section{ABSTRACT}

Kevkep Reşat [Duruöz] was born in Istanbul in 1906. Her father, İzettin Mehmet Reşat was a principal at the of Erenköy High School for Girls, and later director of Darülfünun's School of Dentistry and Pharmacy. After graduating from high school, she received her diploma in chemistry in 1926 from the Darülfünun Faculty of Science. Subsequently she was appointed assistant to the Institute for industrial and bio-chemistry, chaired by Müderris Dr. Cevat Mazhar. She was one of the first female academicians of the Istanbul University (Darülfünun) Faculty of Science. Her research on 'Yoghurt from Istanbul' was published in German in Chemiker-Zeitung, 56. Jhrg., Nr. 5, 1932 (Co-authors: Cevat Mazhar, and Hatice Bodur). Duruöz's career in chemistry was terminated with the University Reform of 1933. She also pursued teaching Turkish, History, Geoghraphy, at secondary schools in Istanbul: Notre Dame de Sion and Saint Benoît. In 1936, she acted as science teacher at Kumkapı Ortaokulu. She left teaching in 1942 after suffering a stroke, and passed away in 1994.

Keywords: Kevkep (Kewkep) Reşat, Hatice Kevkep Duruöz, Istanbul University (Darülfünun) Faculty of Sciences, Cevat Mazhar, chemistry bibliography, history of basic sciences 


\section{Giriş}

Kevkep Hanım, 1930lu yılların bilim evreninde kuyruklu yıldız gibi 1şıldayarak akıp geçmiş bir isimdir. Yayımlanmış tek bilimsel çalışması onun solgun portresinin bir çerçevesi gibidir. ${ }^{1}$ Bu yazıda Kimyager Kevkep Reşat'ın biyo-bibliyografyası üzerinde düzeltmeler yapılarak yaşamöyküsü aydınlatılmaya çalışılacaktır.

Erdal İnönü, 1982’de yayımladığı 1923-1966 Dönemi Türkiye Kimya Araştırmaları Bibliyografyası ve Bazı Gözlemler² başlıklı çalışmasında: 'Kevkep, Reşat' (Reşat Kevkep) için 'Kimya dallarında 1923-1966 döneminde yayınladığı yazı [sayısı]: 3' bilgisi vardır. Reşat $(\text { Kevkep) })^{3}$ adıyla yapılan yayınlar aynı bibliyografyada şöyle sıralanmıştır: ${ }^{4}$

Mazhar, Cevat, (Bodur), Hatice, Reşat, Kevkep, 'Yoghurt from Istanbul' (sic) Chemiker Zeitung, 56, 46-47, CA [Chemical Abstracts] 26 (1932), 2010 (The Fermentation Industries)

Ligor (Bey), Reşat (Bey), Valensi, Gabriel, 'Sur la titrimétrie des sucres', Comptes rendus des séances de l'Académie des Sciences, 196 (1933): 546-548.

Ligor (Bey), Reşat (Bey), Valensi, Gabriel, 'Dosage cuprométrique des sucres en présence d'ammoniaque', Bulletin de la Société Chimique de France, 53 (1933): 407-416.

Kevkep Hanım'ın isminin (baba adıyla birlikte) Kevkep Reşat olarak yazılışı, soyadı gibi: 'Reşat, Kevkep' olarak dizilince, Kevkep Reşat Hanım'a ait bir çalışma ile Ahmet Reşat Bey’e (Alasya, 1900-1958) ${ }^{5}$ ait iki çalışma karıştırılmış; bunun sonucunda adıgeçen bibliyografyada 'Reşat (Bey)' adına üç yayın gösterilmiştir !

Çalışmanın genişletilmiş ikinci basımında, ${ }^{6}$ Kevkep Hanım'ın yazısının künyesinde yazarlar 'Mazhar, Cevat, (Bodur) Hatice, Reşat, Kevkep' olarak sıralanmış; (Çizelge III) 'Kimya bibliyografyasındaki yazarlar ve yazı sayıları' içinde, ${ }^{7}$ Kevkep ve Reşat isimlerine yer verilmediği için, yazar adlarındaki karışıklık gözden kaçmıştır. Buna karşılık, ‘İstanbul yoğurdu’ makalesini

1 Genç Fidanlar Bahçesi. Erenköy İnas Sultanisi’nden Erenköy Kız Lisesi’ne, 1916 - 2016, ed. Elif Sungur, Hakan Aytekin (Istanbul: Şekil Ofset, 2017). '1920’lerde mezun olan Kevkep hanım kimya alanında ilk makalelere imza atmış...'

2 Erdal İnönü, 1923-1966 Dönemi Türkiye Kimya Araştırmaları Bibliyografyası ve Bazı Gözlemler, [1. bs.] (İstanbul: Boğaziçi Üniversitesi yay., 1982), 9. Çizelge III. 'Kimya bibliyografyasındaki yazarlar ve yazı sayıları'.

3 İnönü, 1923-1966 Dönemi, 13.

4 İnönü, 1923-1966 Dönemi, 103-104.

5 Şeref Etker, "Eczacı Kimyager Ahmet Reşat Alasya: kısa yaşamöyküsü,” XII. Türk Eczacılık Tarihi Toplantısı, 1-3 Haziran 2016, Anadolu Üniversitesi, Eskişehir, Bildiri Özetleri (Eskişehir: 2016), 118; Emre Dölen, Eczacı Kimyager Anorganik ve Analitik Kimya Müderrisi Ligor Bey (1877-1956) (İstanbul: Türkiye Kimya Derneği yay., 2017), 72-74 'Ahmed Reşad [Alasya, 1900-1958] Bey'.

6 Erdal İnönü, 1923-1966 Dönemi Türkiye Kimya Araştırmaları Bibliyografyası ve Bazı Gözlemler, [genişletilmiş 2. bs.] (İstanbul: Büke yay., 2007), 162.

7 İnönü, 1923-1966 Dönemi [genişletilmiş 2. bs.], 22-28. 
dört araştırmacı (Cevat Mazhar Bey, Hatice Hanım, Reşat Bey ve Kevkep Hanım) tarafından yazılmış gibi gösteren yayınlar olmuştur.

Son olarak, Erdal İnönü ve Osman Bahadır, Türkiye'de Temel Bilimlerde IIlk Araştırmacılar başlıklı çalışmalarında, ${ }^{8}$ Kevkep Hanım yalnız 'Kimyacı (?)' olarak tanıtıldıktan sonra, özgeçmişi konusunda '1926 yılında Darülfünun Fen Fakültesi'nden “kimyager” unvanıyla mezun olduğundan başka bir bilgimiz yok[tur]' denilmektedir. Bu kitapta da Kevkep Reşat Hanım'a ait yayının yazarları: 'Mazhar, Cevat, Bodur, Hatice, Reşat, Kevkep' olarak verilmiştir.

Kevkep Reşat Hanım hakkında bilinenleri özetleyeck olursak: İstanbul Darülfünunu Fen Fakültesi'nden 1926 yılında 'Kimyager' olarak mezun olmuştur. Aynı fakültede Sınai ve Hayati Kimya asistanlığına atanmıştır. Cevat Mazhar Bey (1873-1934) ${ }^{9}$ ve Hatice Hanım (Vahide Hatice Hasan Bodur, 1902-1993) ile birlikte, İstanbul yoğurtları üzerine bir makalesi bilinmektedir. Sözkonusu yazı, Chemiker-Zeitung (Cöthen/Köthen, Anhalt) dergisinde Almanca yayımlanmış olmasına karşın bibliyografyalarda künyesi İngilizce olarak verilmiştir.

Kevkep Reşat Hanım'ın Müderris Dr. Cevat Mazhar Bey ve asistan Hatice Hasan Hanım ile birlikte hazırladığı 'İstanbul yoğurdu' ile ilgili makalenin başlı̆̆ı şöyledir:"

\section{'Joghurt von Stambul' von Prof.Dr. Djevad Mazhar und den Assistentinnen Hatidje und Kewkep Hanim, Chemiker-Zeitung (Köthen), 56. Jhrg., Nr. 5, 16. Januar 1932, S. 46-47 (Tbl.).}

Makalede, yoğurdun yapılışı ve 'Türk basilleri' ${ }^{11}$ ile oluşumu; yoğurdun Balkan ülkelerine ve Orta Avrupa'da tanınması anlatıldıktan sonra, İstanbul'da Bebek, Kandilli ve Yedikule'den alınan yoğurt örneklerinin kimyasal analizleri özetlenmiştir. ${ }^{12}$ (bkz. EK) 'İstanbul yoğurdu'nun Kevkep Hanım'ın tek bilimsel yayını olduğunu söyleyebiliriz. Başka konularda popüler yazıları olup olmadığını ise bilmiyoruz.

8 Erdal İnönü ve Osman Bahadır, Türkiye’de Temel Bilimlerde İlk Araştırmacılar (İstanbul: Büke Kitapları, 2007), 147.

9 Cevat Mazhar Bey’in doğum tarihi için bkz. Emre Dölen, Türkiye’de Kimya Öğretiminin Tarihçesi (1834-1982) (İstanbul: Türkiye Kimya Derneği yay., 2013), 158, dn. 66.

10 Makalenin künyesi şöyle verilebilir: Cevat Mazhar, Vahide Hatice Hasan [Bodur], Hatice Kevkep Reşat [Duruöz], "Joghurt von Stambul [İstanbul yoğurdu]," Chemiker-Zeitung (Köthen) 56, 5 (16 Januar 1932): 46-47 (tablo).

11 'Türk basili' adı Dr. Ahmet Refik Güran tarafından önerilmiştir, Refik Bey [Güran], 'Recherches bactériologiques sur le "Yo-ourt" et le bacille turc,' Le Lait: revue generale des questions laitieres (Paris), T. 5, no. 47; aoûtseptembre1925: 681-690 (+2 pl., 6 fig.). 'Comme nous avons rencontré ces bacilles granulés dans les Yo-ourts de notre pays et vu qu'il n'a été décrit nulle part, nous lui avons donné le nom bacille turc.' Ayrica bkz., Atilla Özgür, 'Yoğurt - Türk Basili - bir yanılsama mı ?' (özet), IV. Ulusal Veteriner Hekimliği Tarihi ve Mesleki Etik Sempozyumu, 21-23 Mayıs 2014, Samsun, Mersin Üniversitesi Tip Fakültesi Lokman Hekim Tip Tarihi ve Folklorik Tip Dergisi. Haziran 2014 (özel sayı): 21.

12 Yazarlardan Kevkep ve Hatice Hanımlar 'asistan' olarak görterilmiştir. Makalenin yayımlandığı tarihte Kevkep (Reşat) Hanım Sınai ve Hayati Kimya asistanı, Hatice (Hasan) Hanım ise P.C.N. (F.K.B.) Kimya asistanıdır, bkz. Yeşim Işı1 Ülman, 'Hayatı ve çalışmalarıyla bir öncü: Hatice Bodur', Tarih ve Toplum, c. 29, sayı 171, Mart 1998, s. 139/11. 


\section{Hatice Kevkep Hanım'ın kimliği}

Hatice Kevkep (Reşat) Hanım'ın kimlik bilgileri incelenen şu kaynaklardan derlenmiştir: Devlet-i Aliye-i Osmaniye Nüfus Teskeresi (NT.1906), Fen Fakültesi Mezuniyet Rüusu (MR.1926), Tercüme-i hal varakası (TH.1930), İstanbul Darülfünunu Sicil Dosyası (SD.1930), Darülfünun Sicil Hulasası (SH.1931), İstanbul Özel Notre Dame de Sion Fransız Lisesi Arşivi (NDS.1942).

Hatice Kevkep (Hadice Kevkeb) ${ }^{13}$ Hicri 18 Zilkade 1323 [M. 14 Ocak 1906], Rumi 23 Kanunusani 1321 [M. 3 Şubat 1906] tarihinde doğmuştur (NT.1906). İki tarih arasında 20 günlük bir fark görülmektedir. ${ }^{14}$ Doğum yeri: Dersaadet 2. Belediye (Sultanahmet, İstanbul) dairesine bağlı Baba Haydar mahallesi, Arpaemini sokağının 42 numaralı hanesidir. ${ }^{15}$ Hatice Kevkep 'Milleti: Müslime' olarak belirtilmiştir (NT.1906).

Hatice Kevkep'in baba adı İzettin (İzzeddin) Mehmet Reşat Bey’dir (1867- 05.11.1953). Annesi Heybetullah Asiye (Asiye Heybetullah) Hanımdır (NT.1906). Mehmet Reşat Bey öğretmen ve yöneticidir; Erenköy İnas Sultanisi’nde müdürlük yaptıktan sonra, Darülfünun Dişçi ve Eczacı Mektepleri Dahiliye Müdürlüğünde bulunmuştur. Mehmet Reşat Bey, ailesi için 'Duruöz' soyadını seçmiştir.

Hatice Kevkep Hanım, 'iptidai ve lise tahsilini' ${ }^{16}$ yaptı̆̆ 1 Erenköy İnas Sultanisi’nden mezun olmuştur (TM.1930). ${ }^{17}$ Fransızca okuyup yazabilmektedir. Kevkep Hanım, İstanbul Darülfünunu Fen Fakültesi Kimyagerlik programını tamamlayarak Kimyagerlik Mezuniyet Rüusu (lisansı) almıştır. Kendisi, yüksek öğrenimini ‘Darülfünun Kimya Enstitüsü’nde yaptığını belirtmektedir (TH.1930).

Naşid Baylav'ın tanıklığına göre, Kevkep Hanım 1923'te Fen Fakültesi'nin Fizik-Kimya Zümresine (Ulum-1 Fizikiye ve Kimyeviye Zümresi) kayıt olmuştur. ${ }^{18}$ Eczacı Mektebi’ne Eylül 1924’te kadın öğrenci alınınca bu okula kayıt yaptıran Kevkep Hanım’ın, öğretim yılı başlamadan ya da başladıktan bir süre sonra, Fen Fakültesi'ne döndüğü anlaşılmaktadır.

13 Arap harfleriyle: Hadice Kevkeb olarak yazılmıştır (SD.1930).

14 Kevkep Hanım'ın İstanbul Darülfünunu Sicil Defterinde (no. 442) ve Mezuniyet Rüusunda doğumu R. 1321. Nüfus teskere varakasındaki Hicri ve Rumi tarihler farklı olsa da 1906 doğumlu olduğunu kanıtlamaktadır.

15 Adres günümüzde Eyüp ilçesine bağlı Nişancı Mahallesinin Zahireci sokağıdır.

16 Kevkep Hanım, Tercüme-i halinde 'iptidai ve lise tahsili Erenköy Lisesinde ikmal etti[ğini]' belirtmektedir. Erenköy Kız Lisesi, 1915’te Erenköy İnas Numune Mektebi olarak açılmış, 1916 yılında Leyli ve Nehari İnas Sultanisi'ne dönüştürülmüştür. Beş yıl ibtidai ve beş yıl tali olmak üzere 10 yıllık eğitim programı olan inas sultanilerinin bir ana sinıfı da vardı.

17 Kevkep Hanım'ın Tercüme-i halinde liseden mezuniyet tarihi yazılmamıştır. Lise mezuniyeti 1923'dür.

18 Naşid Baylav, Eczacılık Tarihi (İstanbul: Yörük Matbaası, 1968), 267, 'Bunlardan 289 Kevkep Hanım [Eczacı] mektebin eski dahiliye müdürü Reşad Beyin kızı olup defterde [Türkiye İstanbul Darülfünun Tıp Fakültesi Eczacı Mektebi talebelerinin sicil defteri] hizasına hiçbir şey yazılmamış olmakla beraber, bu hanım 1923 senesinde Fen Fakültesi kimya şubesine kayıt olmuştur.' Naşid Baylav 1923 yılında Eczacı Mektebi'nden mezun olduktan sonra Fen Fakültesi'nde kimya öğrenimine başlayınca Kevkep Hanım ile 1923-1926 yıllarında sınıf arkadaşı olmuştur. 
Hatice Kevkep Hanım Fen Fakültesi’nde üç yıllık öğrenimini tamamlayarak 1926 Haziranında 'Kimyager' olarak mezun olmuştur. ${ }^{19}$ Hatice Kevkep Hanım'ın kimyagerlik diploması sureti aşağıda verilmiştir (MR.1926): ${ }^{20}$

\section{Türkiye Cumhuriyeti}

İstanbul Darülfünunu Fen Fakültesi Mezuniyet Rüusu

İstanbul Darülfünunu Fen Fakültesi talebesinden Mehmet Reşat Beyin kerimesi bin üçyüz yirmi bir tarihinde İstanbulda mütevellit Hatice Kevkep Hanım 925-926 senei tedrisiyesinde Kimyayı gayri uzvî ve tahlilî, Kimyayı uzvî, Kimyayı hayatî, Kimyayı sinaî uzvî ve gayri uzvî derslerinden bilimtehan herbirinden tastikname ahz eylemiş olduğundan Fen Fakültesi Talimatnamesine tevfikan işbu Kimyagerlik Mezuniyet Rüusu ita kılındı. 20 Haziran 1926

$\begin{array}{llll}\text { Maarif Vekili } & \text { Darülfünun Emini } & \text { Fakülte Reisi } & \text { Fakülte Katibi umumisi } \\ \text { Mustafa Necati } & \text { Nurettin Ali [Berkol] } & \text { Hüsnü Hamit [Sayman] } & \text { Hüseyin Sabri [Okutman] }\end{array}$

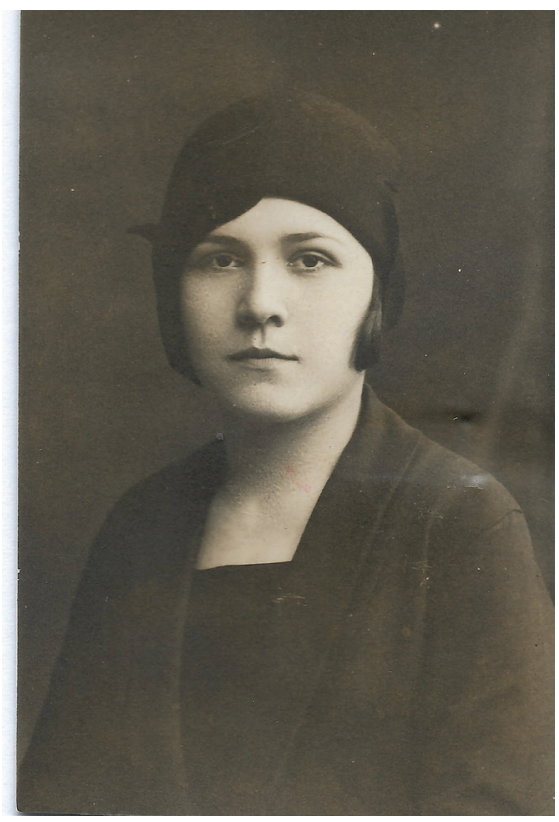

Hatice Kevkep Reşat Hanım

Fen Fakültesi Kimya-yı Sınai ve Hayati asistanı, 1930 (Ş. Etker arşivi)

19 Emre Dölen, “Cumhuriyet'in ilk on beș yılında İstanbul Üniversitesi'nde kız öğrenciler,” Sağlık Alanında Türk Kadını. Cumhuriyet'in ve Tıp Fakültesi'ne Kız Öğrenci Kabulünün 75. Ylll, ed. Nuran Yıldırım içinde (İstanbul: Novartis, 1998), 32, çizelge 7. '1925-1926 Ders y1lı: Kevkep (Reşat), Fen Fakültesi Kimya Enstitüsü’nde Sınai Uzvi Kimya Asistanı’ (1933).

20 Mezuniyet Rüusu ve Sicil Defteri suretlerindeki farklı yazım korunmuştur: 'tastikname', 'Kimyayı gayri uzvî' vb. biçimindeki yazılışlar düzeltilmemiştir. 
Hatice Kevkep Hanım'ın mezun olduğu yıl içinde, 28 Eylül 1926 tarihinde öğretmenliğe (Sicil no. 931) başlamıştır (NDS.1942). Kevkep Hanım, 1 Şubat 1927'de İstanbul Darülfünunu Fen Fakültesi'nde Müderris Dr. Cevat Mazhar Bey'in ${ }^{21}$ yönetiminde bulunan Kimya-y1 Sınai-i Uzvi ve Hayati asistanlığına tayin olmuştur. Kevkep Hanım'ın Darülfünun Fen Fakültesi’nde bulunduğu 1927-1933 yıllarındaki görevleri, atanma tarihleri ve baremi şöyledir (SD.1930, SH.1931):

Tayin: 1 Şubat 1927 Fen Fakültesi Kimya-i Sınai (Kimya-i Sınai ve Hayati) ${ }^{22}$ asistanlığı (maaşı: 1500 kuruş) $)^{23}$

1 Haziran 1928 Fen Fakültesi Kimya-i Sınai-i Uzvi²4 asistanlığı

(Zammile maaşı: 2000 kuruş)

1 Eylül 1931 Fen Fakültesi Hayati Kimya asistanlığı (2500 kuruş) $)^{25}$

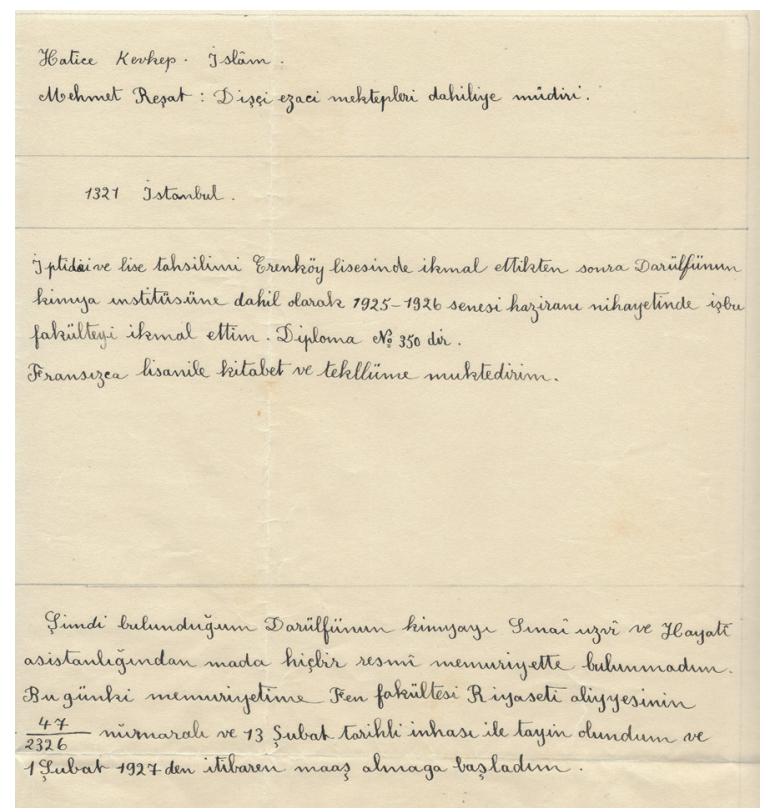

Kevkep Hanım'ın Tercüme-i hal varakası suretinin bir bölümü

(Ş. Etker arşivi)

21 Osman Bahadır, "Darülfünun Kimya Müderrisi Cevad Mazhar Bey niçin intihar etti ?” Toplumsal Tarih 10, 60 (Aralık 1998): 30-32 [Osman Bahadır, Bilim Cumhuriyetinden Manzaralar (İstanbul: İzdüşüm yay., 2000), 33-40]; Şeref Etker, "Dr. Cevat Mazhar Bey nasıl intihar etti ?" Cumhuriyet Bilim Teknik say1 730 (17 Mart 2001): 18; Şeref Etker, "Political Chemistry Across the Baghdadbahn: The Three Lives and Death of Dr. Cevat Mazhar." Modernizers: Changing Science \& Society in the Middle East and North Africa (1870s-1930s), Colloque international'de sunulan bildiri. Paris, Université Paris Diderot, 24 \& 25 juin 2015.

22 SD.1930: Kimya-i Sınai; SH.1931: Kimya-i Sınai ve Hayati.

23 Asistan Hatice Kevkep Hanım'ın İstanbul Darülfünunu Sicil Dosyasında (SD.1930) ‘maaşı', Darülfünun Sicil Hulasasında (SH.1931) 'aylı̆̆ı' olarak belirtilen ücretler 'maaş-1 aslisi (derecesi)' olarak anlaşılabilir. Sicil Dosyasındaki bir diğer kayıt: '1 Eylül 1931'de Barem Kanunile maaşı yirmibeş liraya iblağ olunduğu'.

24 Darülfünun Sicil Hulasası (SH.1931) içinde yazılışı: 'Kimyai Sınaî̂ Uzvî’ (Organik Sınai Kimya).

25 SH.1931. Kevkep Hanım 1930 tarihli sicil kalemi yazışmalarında yine 'Kimyayı Sinai Uzvi ve Hayati asistanı' olarak gösterilmiştir. Kendisi de ‘Kimya-yı Sınai-i Uzvi ve Hayati asistanı’ olduğu bilgisini vermektedir (TH.1930). 
Kevkep Hanım, Fen Fakültesindeki asistanlığı süresince Kimya-yı Hayati ve Sınai Enstitüsü'nde kalmıştır. ${ }^{26}$ Tercüme-i halinde 1930 yılında 'Darülfünun Kimyayı Sınai ve Hayati asistanı' olduğunu bildiren Kevkep Hanım, ek görev olarak 17 Ekim 1931'de İstanbul'da Notre Dame de Sion Fransız Kız Lisesi'nde öğretmenlik yapmaya başlamıştır (NDS.1942).

\section{3 Üniversite Reformu sonrası}

Kevkep Hanım'ın Üniversite Reformu sırasında Darülfünun Fen Fakültesi'ndeki görevinden ayrılmak zorunda kaldığı anlaşılmaktadır (31 Temmuz 1933). İstanbul Üniversitesi’nin kuruluşu sırasında yönetimin atama, azil ve açığa alma uygulamaları yanında istifa edenler de olmuştur. Kevkep Reşat Hanım'ın Darülfünun sicil defterinde Fen Fakültesi’nden ayrılışı ile ilgili bir kayit yoktur.

Kevkep Reşat Hanım'1, Darülfünun asistanlığından sonra, İstanbul'daki Fransız Notre Dame de Sion ve Saint Benoît okullarının öğretmeni olarak görüyoruz. Kevkep Hanım, 1936 yılında İstanbul'da Kumkapı Ortaokulu'ndaki bir yıllık Fen Bilgisi öğretmenliği dışında, Notre Dame de Sion Fransız Kız Lisesi'nin hazırlık kısmında Türkçe, lisesinde tarih ve coğrafya; Saint Benoît' da ise Türkçe öğretmenliği yapmıştır. ${ }^{27}$ Öğrencileri Kevkep Hanım’ı bilgili, 'ciddi fakat insancıl' bir tarih öğretmeni olarak anımsayacaklardır. ${ }^{28}$ Kevkep Hanım, tarih öğretmeni olarak 1937'de İstanbul'da toplanan İkinci Türk Tarih Kurultayı'na katılmıştır. ${ }^{29}$ Kevkep Hanım, Notre Dame de Sion lisesinde öğretmenlik yaparken geçirdiği bir 'felç' nedeniyle, 1942 yılının Ekim ayında bu görevinden ayrılmıştır. ${ }^{30}$

Önce kimyagerlikten, ardından öğretmenlikten ayrılmak zorunda kalan Hatice Kevkep Duruöz’ün izleyen yıllardaki yaşamı konusunda bilgimiz bulunmamaktadır. Fen bilimlerinden tarih-coğrafya ve Türkçe öğretmenliğine geçişinin hangi koşullarda gerçekleştiği de yanıtını bilemediğimiz bir başka sorudur. Hatice Kevkep Hanım'ın kızkardeşleri Fatma Leman Duruöz (1899-17.06.1964)31 ile Emine Muazzez Busayri (1905-18.10.1995) 32 hanımlar da öğretmenlik yapmışlardır.

26 Dölen, Türkiye’de Kimya Öğretiminin, 109.

27 Üniversite Reformu ile açıkta kalan Darülfünun asistanlarının durumları özel olarak incelenmemiştir. Müderris ve muallimler gibi yarım maaaş alan asistanların gelir kayıplarının karşılanabilmesi için Maarif Vekaleti’nin boş bulunan öğretmen kadrolarına (uzmanlık alanı gözetilmeden) atandığı görülmektedir.

28 Liji Pulcu Çizmeciyan, İstanbul'da Kayıp Zamanlar [I] (İstanbul: Türkiye İş Bankası Kültür yay., 2010 ), 77. 'Tarih hocamız, süssüz püssüz, temiz yüzlü biri, Kepkev Hanım (sic). Ciddi fakat insanc1l, iyi nasihatler veren, adeta sörlerin sivil örneği. Tarihi öyle iyi anlatıyor ki, evde hiç okumasan da dersini bilirsin. Tabii, bu dersi iyi dinleyenler için geçerli.'

29 İkinci Türk Tarih Kongresi [İkinci Türk Tarih Kurultay1 1937], İstanbul, 20-25 Eylül 1937, Kongrenin Çalışmalarl, Kongreye Sunulan Tebliğler (İstanbul: Türk Tarih Kurumu yay., 1943), xvii, 'İkinci Türk Tarih Kongresine iştirak edenler. D. Orta Öğretim Tarih Öğretmenleri: Kevkep, Notr Dam Dö Sion Lisesi.’

30 Notre Dame de Sion Fransız Kız Lisesi’nin 1944 yılı mezunu Jozefin Liji Çizmeciyan ile özel görüşme (İstanbul, 14 Mart 2019). NDS.1942 'gittiği tarih' olarak Ekim 1942 gösterilmiştir.

31 'Leman Duruöz’ (Vefat), Cumhuriyet, 18.06.1964. Leman Duruöz Hanım Ankara’ da öğretmenlik yapmıştır.

32 Muazzez Busayri, Libya’nın Dışişleri Bakanı (1954) ve Türkiye Büyükelçisi (1964-1969) olan hukukçu Abdüsselam El-Buseiri (Busairi/Busayri, Trablusgarp 1898 - İstanbul 1978) ile evlidir. Abdüsselam Buseyri, 
Kimyager-öğretmen Hatice Kevkep Duruöz 30 Eylül 1994 tarihinde İstanbul'da vefat etmiştir. $^{33}$

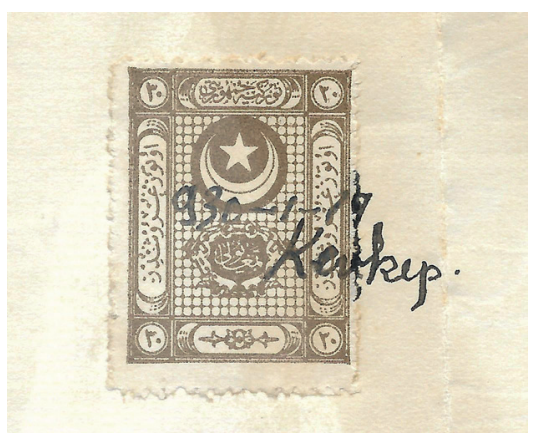

Kevkep Reşat'ın imzası

(Ş. Etker arşivi)

\section{Sonuç}

Erdal İnönü’ye göre, Türkiye'de 1933 öncesinde kimya araştırmaları alanında “uygulama ile ilgili iki yazı: "İstanbul Yoğurtu” (Cevat Mazhar, Hatice Bodur, Reşat, Kevkep) ile Yalova kaplıca suları (M. Faillebin, C. Mazhar, L. Taranakidis, İ. Cıvaoğlu) hakkındaki çalışmalardır”. ${ }^{34}$ Kaynaklarından alınan örnekler üzerinde yapılan bu analizlerin kimya yayınları içindeki özgünlüğüne dikkat çekilmiştir. Yalova termal sularının analizi üzerindeki çalışma Fransa'da yayımlanırken, ${ }^{35}$ Dr. Cevat Mazhar Bey 'İstanbul yoğurdu konulu makaleyi Almanca yayımlamayı seçmiştir. ${ }^{36}$

1930lu yıllarda T.C. Dışışleri Bakanlığı'nda hukuk ve basın müşavirliği yanında İtalyanca çevirmenliği yapmış; ayrıca Devlet Konservatuarı'nın İtalyanca öğretmeni olmuştur. Abdüsselam El-Buseiri, 1936-1937 yıllarında Türkiye Radyolarının Hatay ve Suriye'ye yönelik Arapça haber yayını El-İzaatü'l-Arabiye'nin sorumlusu olmuştur. Bkz. Abdullah Muradoğlu, “Atatürk’ten Arapça Radyo Gazetesi”, Türkiye ve Dünya Yarın, Mayıs 2002, erişim 3 Eylül 2019, yazılacak http://yarin1 ist.tripod.com/mayis/34.htm

33 H. Kevkep Duruöz'ün (1906-30.09.1994) kabri Feriköy mezarlığındadır (21 Ada/18 Ada).

34 İnönü, 1923-1966 Dönemi [genişletilmiş 2. bs.], 31.

35 "Analyse des eaux thermales de Yalova (Turquie d'Asie)," başlıklı makale için, bkz. Emre Dölen, Eczacı Kimyager Anorganik ve Analitik Kimya Müderrisi Ligor Bey (1877-1956) (İstanbul: Türkiye Kimya Derneği yay., 2017), 82-85. Bu makalenin yazarları: Cevad Bey, 'Kimya Enstitüsü Direktörü’, Ligor Bey, 'anorganik ve analitik kimya Profesörü', Faillebin, 'fiziko-kimya ve elektro-kimya Profesörü’ olarak tanıtılmıştır. İlhami Bey, fiziko-kimya muallimidir. Çalışmaya katıldığı belirtilen inorganik kimya asistanı Yakup Kemal Bey’in adı yazarlar arasında geçmemiştir. 'A ces opérations ont participé, outre les membres de la Commission: Illhami Bey, Muallim de chimie physique, et Yacoub Kemal Bey, Assistent de chimie inorganique.' (şekil 77, s. 285).

36 Dr. Cevat Mazhar Bey'in Chemiker-Zeitung'da 1903 yılında yayımlanmıș 'Türkiye'de kimyacıların durumu üzerine' başlıklı kısa bir yazısı vardır. Yazıda, geleneksel üretim yöntemlerini aşamayan Türkiye'nin kimya sektöründe yabancı yatırımcılara firsatlar sunduğu; devletin teşvikleriyle Avrupalıların kurduğu fabrikalarda çoğunlukla Alman kimyacıların çalıştırıldığı; özellikle, fes yapımı fabrikasının çok kazançlı bir yatırım olacağı, yeni feshanenin yerli boya sanayisini de geliştirebileceği anlatıldıktan sonra, Hamidiye Etfal Hastahane-i Alisi'ndeki modern kimya laboratuarına değinilmektedir:

"In der Türkei ist die Lage der Chemiker, sowie der Chemie selbst, eine noch etwas bedenkliche; trotzdem die Türkei viele wertvolle Naturprodukte liefert, fehlen die Elemente für die Verarbeitung derselben, und deshalb werden die Rohmaterialen zur Verarbeitung meistens nach Europa geschickt. Die Türkei wird noch lange kein 
Uygulamaya yönelik bu iki çalışmanın araştırmacılarının yaşamöyküleri, belirli yönleriyle Türkiye' de kimya araştırmalarının kritik bir dönemini yansıtmaktadır: Fen Fakültesi'nin kimya müderrisleri Dr. Cevat Mazhar ve Ligor (Gregorios Taranakidis) Beyler yeni üniversitenin kadrosuna alınmamıştır. Profesör Marius-Mathieu-Joseph Faillebin Fransa'ya dönmüş; İlhami Cıvaoğlu Yüksek Mühendis Mektebi'ne geçmiştir. Hasan Hanım [Bodur] Ord.Prof. Fritz Arndt'ın yönetimindeki Umumi Kimya Enstitüsü'ne reformdan iki yıl sonra, 1935 'te dönebilecektir. ${ }^{37}$ Dr. Cevat Mazhar'ın yerine Avusturyal1 Prof.Dr. Reginald Oliver Herzog getirilince, ${ }^{38}$ frankofon olan Kevkep Hanım'ın Fen Fakültesi’ne dönme şansı kalmamıştır.

Industriestaat sein, da sich ihre Erzeugnisse nur auf eine alte primitive Hausindustrie beschränken. Erst in neuster Zeit, seitdem die Europäer hier einige Fabriken gegründet haben, haben auch manche Inländer es nachgeahmt und einige Fabriken gegründet, von denen manche sich in besten Gange befinden, die anderen aber, die mit dem übrigen Europa nicht konkurrieren konnten, mußten den Betrieb einstellen, und dadurch wurden selbstverständlich die nur noch an geringer Zahl vorhandenen Kapitalisten ihrer Unternehmungslust beraubt und abgeschreckt. Nur hier und da sieht man Fabriken nach europäischer Art. Es wird hier meistens in kleinen Fabriken die sog. Hausindustrie von Inländern selbst betrieben. Beispielweise werden Teppiche, Seiden- und Ledererzeugnisse, Wollen- und Baumwollen-Spinnerei-Artikel, Glas, Seifen, Öle u. a. nicht fabrikmäßig, sondern gewerbsmäßig hergestellt, d. h. die Erzeuger arbeiten jeder selbständig für sich im Hause. Die Farben für die Teppiche werden meist noch nach alten Rezepten selbst dargestellt, $d$. h. man ist eigener Chemiker. Dieser Zustand könnte sehr gut umgewandelt werden, aber leider fehlt es an den Kapitalien, deshalb ist hier für die Kapitalisten die Aussicht auf hohe Verzinsung vorhanden. So gibt es hier infolge Mangels an Kapitalien keine außerordentliche Fabrik, und ohne Fabriken können natürlich keine Chemiker Stellung finden. Der Staat interessiert sich sehr für die Hebung der Industrie und tut sein Möglichstes zu ihrem Aufschwung. Die Errichtung einer Fabrik ist durch Gesetzgebung erleichtert, da seit langer Zeit das Gesetz besteht, daß die für eine Fabrik erforderlichen Maschinen zollfrei eingeführt werden können, bisweilen die erzeugten Waren für einige Jahre für steuerfrei erklärt werden. Wenn z. B. ein Großkapitalist eine Fezfabrik hier errichten würde, so könnte er jährlich gewiß eine große Summe profitieren, da ja Feze für die Türkei unentbehrlich sind und für die Nationalkopfbedeckung viele gebraucht werden. Es gibt keine einzige Fabrik für die Erzeugung des Fezes im Lande selbst, daher würde der Staat gewiß sehr behilflich sein, und es würden dann einige Färberei-Chemiker Stellung finden.

Nach vorstehenden Ausführungen ist es selbstverständlich, daß Chemiker hier sehr spärlich vertreten sind, denn es gibt hier keine speziellen Laboratorien, in denen Chemiker ausgebildet werden könnten, und über die Laboratorien, die existieren, verfügt der Staat selbst, weil sie zu Staatszwecken benutz werden. So darf man beispielweise hoffen, daß das vom Sultan erst neu errichtete, mit allem Komfort ausgestattete und mit den empfindlichsten Instrumenten versehen chemische Laboratorium im Hamidin-Kinderkrankenhause [sic] zu einer solchen Ausbildungsanstalt bestimmt wird. Die in den Fabriken angestellten Chemiker sind meistens Ausländer, von denen Deutschen in der Mehrheit vorhanden sind. Was das Gehalt anbetrifft, so schwankt es zwischen 600 und 300 M[ark] monatlich, je nach Leistungen. Noch ist zu bemerken, daß Chemiker, welche mit den hiesigen Verhältnissen nicht vertraut sind, gewarnt werden müssen, nicht ohne vorherige feste Vereinbarungen hierher zu kommen."

Dr. Djewad Mashar (Konstantinopel), “Über die Lage der Chemiker in der Türkei,” Chemiker-Zeitung 27, 66 (1903): 806.

37 Ülman, "Hayatı ve Çalışmalarıyla,” 139/11. Dölen, Türkiye'de Kimya Öğretiminin, 201, Çizelge 4.2. 'Asistan Hatice Hasan [Bodur] Hanım'.

38 Prof. Herzog'un 1935 'te ölümünden sonra yerine bir başka Avusturyalı Prof.Dr. Philipp Groß (Gross) getirilmiştir, Emre Dölen, Türkiye Üniversite Tarihi, 4: İstanbul Üniversitesi (1933-1946) (İstanbul: İstanbul Bilgi Üniversitesi yay., 2010), 466. Philipp Gross, biyografilerinde İstanbul Üniversitesi'nde 'Misafir Ordinaryüs Profesör ve Uygulamalı Kimya Enstitüsü Direktörü' olarak gösterilir ('ordentlichen Gastprofessors und Direktors des Instituts für Angewandte Chemie an der Universität Istanbul'). 
Kevkep Reşat'ın 1923'te Darülfünun Fen Fakültesi'ne öğrenci olarak girişi başlangıç alınırsa, kimya çalışmalarını on yıl kadar sürdürdüğünü söyleyebiliriz. Kevkep Hanım, asistanlığını yaptığ 1 Dr. Cevat Muhtar Bey’in üniversite reformuyla akademik yaşamdan dışlanmasından kısa bir süre sonra, 11 Mart 1934 tarihindeki ölümünden etkilenmiş olmalıdır. Hatice Kevkep Hanım'ın biyografisi ne yazık ki, sağlığında yazılamamıştır. Bu nedenle, kimyagerlikten ayrılış kararında özellikle hangi olay ve düşüncelerin belirleyici olduğunu bilemiyoruz. Yarım kalmış ve yayımlanamamış çalışmalarının bulunabileceğini sanıyoruz. Fen bilimleri yerine tarih ve Türkçe öğretmenliğini seçmiş olmasının kimyagerlik kariyerinin son yıllarında yaşadıklarına bir tepki olarak yorumlanabileceği kanısındayız. Sunulan kısa yaşamöyküsü ile H. Kevkep Duruöz'ün Türkiye'de temel bilimlerde ilk araştırmacılar arasında daha geniş bir yer edinebileceğini umuyoruz. ${ }^{39}$

\section{EK}

Cevat Mazhar, Hatice Hasan ve Kevkep Reşat'ın 'İstanbul yoğurdu' konulu çalışması

'Joghurt von Stambul' von Prof.Dr. Djevad Mazhar und den Assistentinnen Hatidje und Kewkep Hanim, Chemiker-Zeitung (Köthen), 56. Jhrg., Nr. 5, 16. Januar 1932, S. 46-47 (Tbl.).

\section{Chemiker-Zeitung}

Verantwortlicher Schriftleiter: Prof. Dr. Walter Roth.

\begin{tabular}{|c|c|}
\hline 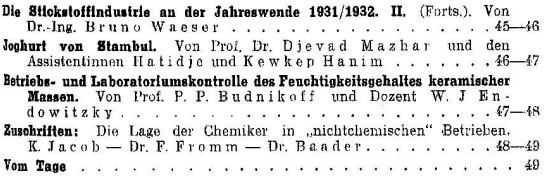 & 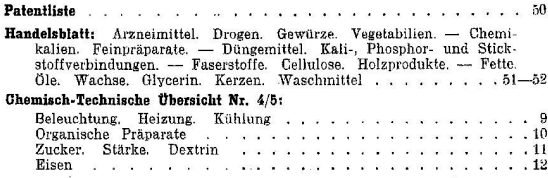 \\
\hline Nr. 5, S. $45-52$ & 56. Jahrgang \\
\hline
\end{tabular}

Joghurt von Stambul.

i Von Prof. Dr. Djevad Mazhar und den"Assistentinnen Hatidje und Kewkep Hanim.

Auch die Türken haben, wie so viele Völker, eine besondere Bei der Zubereitung des thrkischen Joghurts muB der Arbeitsraum Art gegorener Milch, den sogen. Joghurt. Infolge der Einfachheit und eine gleichmälige Temperatur (nämlich $45^{\circ} \mathrm{C}$ ) aufweisen. Man kocht Lcichtigkeit seiner Herstellung, wie besonders auch infolge der in den die Milch, unter fortwährendem Rühren mit einem Löffel, damit sich letzten Jahren geglückten Reinkultur der spezifischen Joghurtbazillen, kein Rahm bildet, bis etwa auf \%s oder sogar bis zur Halffte tin, stellt der sogen. „Turkischen Bazillen“, hat der Joghurt sich nicht nur in der dann die Schüsseln, in denen man den Joghurt zubereiten will, in eine Türkei und in den Balkanlzzdern, sondern auch uber diese Gebiete mit Stroh versehene Kiste und fullt die Schusseln mit der eben abgehinaus in Mitteleuropa verbreitet. Heute wird Joghurt auch in Europa kochten, etwas dick gewordenen Milch auf. Für 1 l Milch verwendet viel verlangt, als Nahrungsmittel wie als Delikatesse; seine Verbrei- $\operatorname{man} 10-12$ g von $2-3$ Tage altem Joghurt als Gärungsmittel, vertung verdankt er nichi nur seinem guten Geschmack, sondern auch dünnt den Joghurt mit einem Teil der abgekochten, kalt gewordenen seiner reichen Mikroflora, die den Vitamingehalt des Joghurts noch be- Milch und hălt dann zur Einspritzung bereit. Wenn die gefallten deutend erhöht. Dazu wirken die Joghurtbakterien auf den Darm Schusseln bis auf $42-40^{\circ} \mathrm{C}$ abgekühlt sind, spritzt man mit einer antiseptisch; denn die Joghurtbakterien vertragen die Körperwarme, Glasspritze von dern Rande aus, von verschiedenen Seiten, den zur wahrend durch die von ihnen abgeschiedenen Sauren die septischen Einspritzung bereitgehaltenen, mit etwas Milch verdünnten Joghurt in Miliroorganismen leicht zugrundegehen. Mar glaubt allgenein, daß die Schüsseln. Bleibt die Temperatur konstant, so bildet sich der das Erreichen eines auffallend hohen Alters bei der kleinasiatischen Joghurt in 3-4 Stunden. Will man den zu bereitenden Joghurt nicht Bevölkerung mit dem vielen Genuß von Joghurt zusammenhängt. Fest- ganz sauer haben, so labt man ihn nicht allzulange bei zu hoher gestelt ist jedenfalls, daß bei reichlichem Genuß von Joghurt Verdau. Temperatur stehen. Gutes Kondensieren der Milch bedingt einen ungabeschwerden ausbleiben, was man eben der antiseptischen Wir- schönen Geschmack und erhöht den Năhrwert. Die für therapeutische king des Joghurts aut die Därme zuschreibt.

39 'Joghurt von Stambul' adlı araştırmasının yoğurt bibliyografyasına girmediğini de belirtmeliyiz, bkz. Bülent Ağaoğlu, Yogurt Bibliography (Ankara: Gida Teknolojisi Derneği yay., 2013), erişim 3 Eylül 2019, file:///C:/ Documents\%20and\%20Settings/Owner/Belgelerim/Downloads/Yogurt\%20Bibliography.pdf 
darum zieht man den etwas sauren Joghurt vor; d. h. man lä.Bt den darum sind bei der Untersuchung des Joghurts bestimmte Fordertungen Joghurt Jänger bei hoher Temperatur stehen. Die Eigenschaften des el'- aufzustellen. Wir nehmen an, dab die Bestimmung des Trockenhaltenen Joghurts hängen nicht nur von der Vorbereitung ab, sondern extrakts, des Fettgehalts und der Refraktionszahl des Serums für die auch von dem Charakter der für die Herstellung verwandten Milch; Feststellung des Charakters und der Güte eines Joghurts genügt.

\begin{tabular}{|c|c|c|c|c|c|c|c|c|c|c|}
\hline & $\begin{array}{c}\text { Trockent- } \\
\text { stustanz } \\
\text { sto }_{10}\end{array}$ & $\begin{array}{c}\text { Caspin } \\
\% \\
\end{array}$ & $\begin{array}{c}\text { Fett } \\
i j \\
0 \%\end{array}$ & $\begin{array}{c}\text { Lactoge } \\
\% \\
\end{array}$ & \begin{tabular}{|c|}
$\begin{array}{c}\text { Gesantint- } \\
\text { sâurefeghalt } \\
\text { o\% }\end{array}$ \\
\end{tabular} & $\begin{array}{l}\text { Cehalt an } \\
\text { licichtitien } \\
\text { Saluren \% }\end{array}$ & $\begin{array}{c}\text { Aache } \\
\%\end{array}$ & $\begin{array}{c}\text { Oesaants } \\
\text { stickstoff } \\
0 \% 0 \\
\end{array}$ & $\begin{array}{c}\text { Alkohol } \\
\%\end{array}$ & 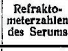 \\
\hline larktmilchprobe $\mathrm{D}(1,025) \ldots \ldots$ & 13,8 & 4,62 & 2,34 & 2,8 & 0,17 & - & 0,77 & 0,494 & & \\
\hline $\begin{array}{l}\text { Joghurtprobe aus Bebek suitanesi } \\
\text { Joghurtprobe von Kandilli. } \\
\text { Joghurtprobe von Yedikule: } \\
\text { von uns }\end{array}$ & $\begin{array}{l}26,08 \\
20,36 \\
14,03 \\
30,75\end{array}$ & $\begin{array}{r}5,58 \\
7,95 \\
7,72 \\
11,87\end{array}$ & $\begin{array}{r}11,4 \\
6,1 \\
3,5 \\
8,2\end{array}$ & $\begin{array}{l}8,0 \\
3,4 \\
1,2 \\
6,2\end{array}$ & $\begin{array}{l}1,86 \\
1,548 \\
1,19 \\
1,32\end{array}$ & $\overline{0,02}$ & $\begin{array}{l}1,02 \\
0,95 \\
0,58 \\
1,48\end{array}$ & $\frac{1,15}{0,9} \frac{1,34}{1,34}$ & $\begin{array}{l}\text { Spur } \\
\text { Spur }\end{array}$ & $\begin{array}{l}1,352 \\
1,352 \\
1,354 \\
1,363\end{array}$ \\
\hline 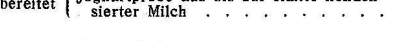 & $\begin{array}{l}32,01 \\
{ }_{4} \mathrm{He}\end{array}$ & 13,07 & $\begin{array}{r}8,78 \\
t^{4} \text { Okt }\end{array}$ & $\begin{array}{l}\quad 7,6 \\
\text { ranalys }\end{array}$ & 1,514 & - & 1,63 & 1,5 & - & 1,363 \\
\hline 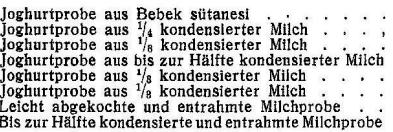 & $\begin{array}{l}24,13 \\
19,9 \\
26,6 \\
37,25 \\
19,93 \\
16,04\end{array}$ & $\begin{array}{r}11,12 \\
7,52 \\
11,35 \\
14,81 \\
11,95 \\
7,74\end{array}$ & $\begin{array}{c}5,23 \\
4,7 \\
6,7 \\
13,26 \\
4,7 \\
3,8\end{array}$ & $\begin{array}{l}5,28 \\
4,9 \\
4,86 \\
7,11 \\
2,05 \\
2,6\end{array}$ & $\begin{array}{l}2,403 \\
1,84 \\
1,58\end{array}$ & $\begin{array}{l}0,0024 \\
0,009 \\
0,036\end{array}$ & $\begin{array}{l}0,87 \\
0,9 \\
0,19 \\
1,83 \\
1,245 \\
1,16\end{array}$ & $\begin{array}{l}0,744 \\
1,5 \\
0,98 \\
0,968\end{array}$ & - & $\begin{array}{l}1,348 \\
1,349 \\
1,352 \\
1,361 \\
1,350 \\
1,347 \\
1,346 \\
1,357\end{array}$ \\
\hline
\end{tabular}
Bis zur abglifte kondensierte und entrahmte Milchprobe

Bestimmung des Trookenextrakts. $20 \mathrm{~g}$ von dem gut durchgerthrten

Asche. Die Trockensubstanz wurde in derselben Platinschale nach bennter Weise calciniert.

Slurebestimmung. Wir haben die gesamte Sture aut Milchsäure und die flüchtigen Săuren auf Essiggäure berechnet. You dem gut dư clhgerührte Joghurt haben wir $10 \mathrm{~g}$ in eine Porzellanschsile gebracht und zunächst nit wenig lauwarmem destillierten Wasser bis zul' Sirupdicke geruhrt, dann den Inhalt der Schale in einen Erlenmeyerlkolben gebracht, auch das Waschwasse mit dem Inhalt des Erlenmeyerkolbens vereinigt und das Ganze mit destiliertem Wasser auf $250 \mathrm{ccm}$ aufgeftult. Dann haben wir ein paar Tropfen Phenolphthalein als Indicator hineingetan und die Losung mit n/10-Natronpliziert, und so haben wir den gesamten Săuregehalt in $10 \mathrm{~g}$ Joghurt ermittel Bestimmung der fltohtigen staren. Die Bestimmung haben wir mit 50 Joghurt ausgefūhrt. $\mathrm{Zu}$ diesem $\mathrm{Zwecke}$ haben wir der Joghurt in einer Porzellanschale mit destilliertem Wasser gut durchgerthrt und dann den Inhalt in einen größeren Kolben ubbergeführt, einige Stacke Siedesteine hineingetan und

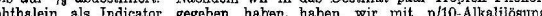
titriert, als lindicator gegeben haben, haben wir mil inlio-Alkalilosung Gehalt an fluchtigen Säuren in $\mathbf{B 0} \mathrm{g}$ Joghurt bestimmt.

Bestimmung des Caseing nnd des Pettgehaltes. Wir haben eine bestinmte Menge von dem gut durchgerihrten Joghurt in einer Porzellanschale abgewogen und zwecks Bintfernung der Feuchtigkeit mit bestimmter Gewichtsmenge gebranntem GiDS und Quarzsand gut durchgerahrt. Die Mischuag trockenen noch einmal mit wenig Ather gevpaschen und auch die Waschflugsigkeit in den Exlenmeyerkolben gebracht. Denn haben wix den Strpsel feast zugemach den Inhalt mehrere Male tichlig gescinttelt und hierauf 24 Stunden an einen Erlenmeyerkolbons ober oin trockenes, tertogenes vorker gewogene Schals filtriert, den Rowckstand mehrere Male mit wenis Ather gewaschen, die Waschilussigkeit dem Filtrat hinzugefügt, die Atherlơsung abgedamptt, die Schale im Trockenschrank bis zur Gewichtskonstan gitrocknet, und dann gewogen. Der gefundene Fettgehall wurde auf 100

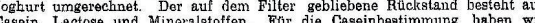
en Riuckstand mehrere Male mit heiBem, destilliertem Wasser, darn einmal mit Alkohol und Äther gewaschen und nach dem Trocknen vorschriftsmaBis

stickstotfbestimmung. Vom gut durchgeruhrten Joghurt haben wir $5 \mathrm{~g}$

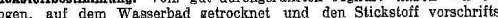
Big bestimnt.

Laotosebastimmung. Die Lactosebestimmung wurde mit $20 \mathrm{~g}$ Joghur ach der Methode von $\mathrm{S}$ ch i ib a ausgefuhrt.

Alkoholbestimmung. Von dem gut durchgerthrten Joghurt haben wir $250 \mathrm{~g}$ abgewogen und mit gleicher Menge destilliertem Wasser vordünn darauf bis zur loicht alkalischen Reaktion einige Tropfen Alkali zugefug das Ganze in einen groderen Kolben hinengetan und nach zusatz von paa tion nach $\mathrm{R}$ i min $\mathrm{i}$ versucht. Zu diesem Zweck haben wir das Destillat in einem Erlenrneyerkolben mit nach Zufügung von paar Tropfen mit Bichronatlősung versetzter verdünnter Schwefelsăure allie paar Minuten auf einem Wasserbad elwärmt. Dann haben wir in das Innere des Erlenmeyerkolben einen Papierstreifen, der mit einer einige Thopfen pipondin enthaltenden Alkohol vorhanden ist, so wird er zu Aldehyd oxydiert, und auf dem Papierbeim Bebek-Joghurt und einmal auch beim Yedikule-Toghurt beobachtet.

Teşekkür/Acknowledgments: Feza Günergun, Liji Çizmeciyan, Emre Dölen, Suzan Sevgi (İstanbul Özel Notre Dame de Sion Fransız Lisesi), Lale Murtezaoğlu (Notre Dame de Sion'lular Derneği, İstanbul), Nadya Lokmagöz (İstanbul Özel Saint Benoît Fransız Lisesi) ve İBB Avrupa Yakası Mezarlıklar Müdürlüğü’ne; ayrıca, düzeltme ve önerileri için makalenin hakemlerine teşekkür ederim.

\section{KAYNAKÇA / BIBLIOGRAPHY}

\section{Arşiv Kaynakları / Archival Sources}

Şeref Etker Arşivi / Archive. Hatice Kevkep Devlet-i Aliye-i Osmaniye Nüfus Teskeresi sureti; Hatice Kevkep Fen Fakültesi Mezuniyet Rüusu sureti, no. 350; Hatice Kevkep Tercüme-i hal varakası sureti; Hatice Kevkep İstanbul Özel Notre Dame de Sion Fransız Lisesi öğretmen kütüğ̈̈; Hadice Kevkeb, İstanbul Darülfünunu Sicil Dosyası, no. 442; Hatice Kevkep, Darülfünun Sicil Hulasası, no. 442 cedit.

\section{Basılı Kaynaklar / Printed sources}

Bahadır, Osman. "Darülfünun Kimya Müderrisi Cevad Mazhar Bey Niçin İntihar Etti?” Toplumsal Tarih 10, 60 (Aralık 1998): 30-32. 
Bahadır, Osman. “Darülfünun Kimya Müderrisi Cevad Mazhar Bey Niçin İntihar Etti?” Bilim Cumhuriyetinden Manzaralar içinde 33-40. İstanbul: İzdüşüm Yayınları, 2000.

Baylav, Naşid. Eczacılık Tarihi. İstanbul: Yörük Matbaası, 1968.

Çizmeciyan, Liji Pulcu. İstanbul'da Kayıp Zamanlar [I]. İstanbul: Türkiye İş Bankası Kültür Yayınları, 2010.

Djevad Mazhar, Hatidje u. Kewkep Hanim [Cevat Mazhar, Vahide Hatice Hasan Bodur, ve Hatice Kevkep Reşat Duruöz]. “Joghurt von Stambul [İstanbul Yoğurdu].” Chemiker-Zeitung (Köthen) 56, 5 (1932): 46-47.

Djewad Mashar [Cevat Mazhar]. "Über die Lage der Chemiker in der Türkei [Türkiye'de Kimyacıların Durumu Üzerine]." Chemiker-Zeitung 27, 66 (1903): 806.

Dölen, Emre. “Cumhuriyet'in İlk On Beş Yılında İstanbul Üniversitesi’nde Kız Öğrenciler.” Sağlık Alanında Türk Kadını. Cumhuriyet'in ve Tıp Fakültesi’ne Kız Ögrrenci Kabulünün 75. Yıll, editör Nuran Yıldırım içinde 8-47. İstanbul: Novartis, 1998.

Dölen, Emre. Türkiye Üniversite Tarihi, 4: İstanbul Üniversitesi (1933-1946). İstanbul: İstanbul Bilgi Üniversitesi Yayınları, 2010.

Dölen, Emre. Türkiye'de Kimya Öğretiminin Tarihçesi (1834-1982). İstanbul: Türkiye Kimya Derneği Yayınlar1, 2013.

Dölen, Emre. Eczacı Kimyager Anorganik ve Analitik Kimya Müderrisi Ligor Bey (1877-1956). İstanbul: Türkiye Kimya Derneği Yayınları, 2017.

Etker, Şeref. “Dr. Cevat Mazhar Bey Nasıl İntihar Etti ?” Cumhuriyet Bilim Teknik sayı 730 (17 Mart 2001): 18. Etker, Şeref. "Political Chemistry Across the Baghdadbahn: The Three Lives and Death of Dr. Cevat Mazhar." Modernizers: Changing Science \& Society in the Middle East and North Africa (1870s-1930s), Colloque international'de sunulan bildiri. Paris, Université Paris Diderot, 24 \& 25 juin 2015.

Etker, Şeref. "Eczacı Kimyager Ahmet Reşat Alasya: Kısa Yaşamöyküsü.” XII. Türk Eczacılık Tarihi Toplantısı, 1-3 Haziran 2016, Anadolu Üniversitesi, Eskişehir, Bildiri Özetleri. Eskişehir: yayl. y., 2016, 118.

Genç Fidanlar Bahçesi. Erenköy Inas Sultanisi'nden Erenköy Kız Lisesi’ne, 1916-2016, editör Elif Sungur ve Hakan Aytekin. İstanbul: Şekil Ofset, 2017.

İkinci Türk Tarih Kongresi [İkinci Türk Tarih Kurultayı 1937], İstanbul, 20-25 Eylül 1937, Kongrenin Çalışmalarl, Kongreye Sunulan Tebliğler. İstanbul: Türk Tarih Kurumu Yayınları, 1943.

İnönü, Erdal. 1923-1966 Dönemi Türkiye Kimya Araştırmaları Bibliyografyası ve Bazı Gözlemler, [1. bs.]. İstanbul: Boğaziçi Üniversitesi Yayınları, 1982.

İnönü, Erdal. 1923-1966 Dönemi Türkiye Kimya Araştırmaları Bibliyografyası ve Bazı Gözlemler, [genişletilmiş 2. bs.]. İstanbul: Büke Yayınları, 2007.

İnönü, Erdal, ve Osman Bahadır. Türkiye’de Temel Bilimlerde İlk Araştırmacılar. İstanbul: Büke Kitapları, 2007. “Leman Duruöz” (Vefat). Cumhuriyet, 18.06.1964.

Özgür, Atilla. "Yoğurt - Türk Basili - Bir Yanılsama mı ?” Mersin Üniversitesi Tıp Fakültesi Lokman Hekim Tip Tarihi ve Folklorik Tip Dergisi, IV. Ulusal Veteriner Hekimliği Tarihi ve Mesleki Etik Sempozyumu, Samsun, 21-23 May1s 2014 özel sayıs1 (Haziran 2014): 21.

Refik Bey [Güran]. "Recherches bactériologiques sur le "Yo-ourt” et le bacille turc." Le Lait: Revue générale des Questions laitières (Paris) 5, 47 (août-septembre 1925): 681-690.

Ülman, Yeşim Işı1. “Hayatı ve Çalışmalarıyla Bir Öncü: Hatice Bodur.” Tarih ve Toplum 29, 171 (Mart 1998): 138/10-142/14. 


\section{Elektronik Kaynaklar / Electronic Sources}

Ağaoğlu, Bülent. Yogurt Bibliography. Ankara: Gıda Teknolojisi Derneği Yayınları, 2013. Erişim 3 Eylül 2019. file://C:/Documents\%20and\%20Settings/Owner/Belgelerim/Downloads/Yogurt\%20Bibliography.pdf

Muradoğlu, Abdullah. “Atatürk’ten Arapça Radyo Gazetesi.” Türkiye ve Dünya Yarın, Mayıs 2002. Erişim 3 Eylül 2019. http://yarin1ist.tripod.com/mayis/34.htm

\section{Sözlü Kaynaklar / Oral Sources}

Jozefin Liji Çizmeciyan ile özel görüşme, İstanbul, 14 Mart 2019. 
